\title{
Nutrition education in the context of early childhood malnutrition in low-resource communities
}

\author{
By J. P. Stanfield, Social Paediatric and Obstetric Research Unit, University of \\ Glasgow, 23 Montrose Street, Glasgow GI IRN
}

\section{Introduction}

Malnutrition of early childhood is the outcome of a number of complex and related factors, insufficiency or imbalance of dietary intake being just one of many. It has been only fairly recently realized, for instance, just how considerable a part recurring infection plays in the stepwise progress of falter and inadequate rehabilitation by which the young child becomes malnourished. Furthermore, dietary intake is reduced or distorted by many other factors than lack of knowledge of what foods are appropriate for the growing child. Shortage of food, both seasonal and sporadic, loss of appetite, maternal deprivation and infection can all reduce intake.

Ignorance, however, plays a large part in the malnutrition of the over-indulged children of the welfare states and in the commonest type of malnutrition, protein-energy malnutrition of early childhood, in low-resource communities all over the world. I intend to concentrate in this paper on the principles of nutrition education as we attempted to deliver it to the mothers of malnourished or 'at-risk' children, and in general to mothers and community leaders in Uganda.

In so doing I hope to point out possible points of application which I believe are common to the problems of both developing countries and the urban deprived in the developed countries. Finally, I hope there will be time to discuss some practical problems of evaluation of nutrition education.

The cause of malnutrition to which education is directed is ignorance or lack of knowledge concerning the nature of food. It is only in the last hundred years or so that science has related what we eat to how we grow and develop, and even now we are only beginning to learn the importance of adequate nutrition for brain growth. In unschooled communities, where traditions and taboos still operate, highly complex conceptions of 'food' exist which have nothing to do with growth and development.

One of the basic reasons for protein-energy malnutrition of early childhood in that part of Uganda where I worked for many years was the sudden weaning of the breast-fed infant onto an adult diet (two or three meals/d) of cooked banana ('matoke'). The staple matoke is the food of the kings and is still regarded in rural families as the traditional food of the Baganda. The family meal centres on the steamed matoke, which is eaten with fingers which dip the matoke into the 'sauce', (groundnut, 'dodo', or other spinach, beans, etc.). Meat and fish are eaten at 
infrequent intervals. The baby weaned suddenly from the breast sits hungry round the food and fills his stomach with matoke with perhaps a flavour of 'sauce'. His malnutrition arises partly from the sheer mechanical impossibility of getting enough energy and protein from matoke in two or three meals/d.

In $1965 \mathrm{Dr}$ I. Schneideman developed a nutrition rehabilitation unit attached to Mulago Hospital where both in-patient and out-patient mothers rehabilitated their malnourished children, and in the process experienced an education intended to prevent recurrence and reduce the incidence of malnutrition in the community at large.

\section{Principles of nutrition education}

The principles of education which gradually evolved during the development of the unit can best be described in mnemonic form for they all seem to begin with ' $i$ ': (1) identification, (2) involvement, (3) indigenous, (4) 'influencers', (5) indoctrination, (6) integration, (7) individuals.

(I) Identification. The first essential of communication is the development of an understanding and rapport between the teacher and the taught. In the classical educational systems this is so difficult to achieve. The teacher is filled with knowledge which he must impart to the ignorant. A one-way flow from donor to recipient prevents any intermingling.

Two simple pictures may illustrate this barrier. Faced with mothers who were feeding their children on cooked banana, and following the discovery by Cicely Williams that kwashiorkor was a disease caused by relative lack of protein intake, the early nutrition teaching was authoritative: 'Matoke is not a good food-you are not feeding your baby properly'.

The attitude of the Baganda mothers, listening politely, was understandable given their concept of 'food' which was 'that which satisfies hunger' and perhaps also 'what is good for the Kabaka to eat is good for my child'. They were feeding their children perfectly well. Furthermore, the mother had learned from her mother that kwashiorkor, or 'obwosi' as it is called in Luganda, is due to heat from the next child developing in her womb and that the child's swelling could be helped by sending her away to a relative, the very action which often precipitated an acute worsening of the malnutrition. The attitude of the teacher was 'these mothers are ignorant - they will never learn'. So both thought the other 'ignorant', and both in a sense were right! But the barrier is complete until someone is prepared to listen. Concepts of food and the nature of the illness were utterly different.

The second example is typical also of the attitude of many in this country. The child with severe malnutrition is brought at length to hospital after many attempts at local treatment. Cure is achieved by tube feeding, intramuscular antibiotics for infection and perhaps other, more dramatic, forms of therapy. Discharged from the ward the mother returns home filled with pleasure and wonder at the marvels of the Western medicine. This illness, whatever its cause, can be cured by hospitals, injections and medicine. How wonderful 'they' are. So there develops a 'they' relationship with the mother who is content to accept that the disease of 
'malnutrition' can be cured by the hospital and has nothing to do with her. Attempts at formal teaching in the hospital, where she lives in a different world unrelated to her own, carry no relevance for her.

Therefore for successful communication of ideas, we must enter a different conceptual framework; we must learn what our words and ideas mean to others. We must also learn the constraints under which those we teach are living so that the teaching can be made applicable to their situation on a 'home budget' in 'home circumstances' (far from perfect). Success comes when the mother is able to say 'we', or better still ' $I$ ', have cured his 'malnutrition' and when she understands that foods available to her are responsible.

So often standard of teaching is equated with content of equipment etc., and it is very difficult psychologically to accept a situation in which content is poor and very limited.

This has application for communities in developed countries. Education for better nutrition and living in general must be done within the community as it is. There is no value in taking the community out of an accustomed environment into a new environment, as has occurred in many rehousing schemes in this country. Change of environment comes from within the community and is accepted by the community because it remains identified with the community and is not something imposed from outside.

(2) Involvement. The second principle is part of a famous proverb concerning methods of learning: 'What I hear, I forget; what I see, I remember; what I do, I know'. In one sense malnutrition is a very satisfying condition, for the 'cure' is the same as the 'prevention', and the improvement in the child is dramatic and very gratifying (it can be demonstrated within a few days) and changes the misery of both child and mother into an infectious joy.

So in nutrition rehabilitation the mother is involved in the cure at all stages. As medical care recedes, lay care takes over, and no vacuum of dependance is allowed to develop. If this cure can be effected out of hospital, as near home as possible, with food that the mother is familiar with and can grow, prepare, cook and feed to her child herself, so much the better. As a result rural rehabilitation centres were developed in which the mother, under supervision, cultivated and cooked food and fed her child herself and watched the child get better. In this way it was hoped that she would relate the cure to what she had done. We kept white coats, and stethoscopes, and injections as far away as possible and cultivated cows and chickens, rabbits and food crops.

We capitalized on the cure: and this has been done with other diseases such as diabetes, leprosy, and tuberculosis. But how slow the medical profession is to involve the patient and his relatives in the curel The desire to preserve professional detachment and esteem, the effort of attempting to understand different concepts and the ease of management without parents getting in the way and disturbing the neatness and tidiness of institutional routine are some reasons for the backwardness of health education in this country.

The most important involvement of all is the use of the mothers in teaching. After a week or two in the unit, the mothers have learned enough to be able to 
demonstrate food preparation and feeding to the new arrivals, or to the outpatients. They become remarkably good and seem to suffer little embarrassment; some of them make very good teachers. On discharge they are followed home and meetings are arranged locally at which they demonstrate to neighbours or the local club what they have learned.

(3) Indigenous. The method of communication must be indigenous and this requires fairly detailed information of the culture. The use of proverbs, songs, mimes, rhymes, drama or wall pictures will vary depending on the way people communicate. At the lowest level 'gossip' is the commonest and most universal mode, and one nutrition educator installed a tape recorder behind a mirror around which the mothers at the end of the clinic gathered to tidy themselves. He learned a great deal from the 'gossip' which went on as they completed their toilet, about what the mothers had learned and what they thought of the clinic and the teaching.

The name of the clinic is important in this respect and the words used for foods must be local and meaningful. 'Mwanamugimu' was the title given to the nutrition rehabilitation unit in Kampala, after a great deal of thought. It was suggested by the Ugandan staff from the first words of a Luganda proverb meaning: 'The healthy child comes from good roots'. The title emphasized the positive endproduct of the clinic: how much better than the 'Malnutrition' or the 'Kwashiorkor Clinic'! The name has become almost a local legend. Likewise the name of the mixtures of food with which the children are fed (a 'Heinz' type mixed food in which the staple matoke forms an excellent base for pounded groundnuts or dried fish, or beans etc.) was adopted from a local word meaning a 'good, mixed food': 'kitobero'. There was a popular song about 'kitobero' so the name brought laughter and understanding. The solution to a problem very often lies within the rich tradition of the culture if it can only be tapped by local people who can live in two cultural frameworks.

These people who act as interpreters of the message which it is desired to communicate are very helpful. My colleague who was a musician had composed a number of songs about the way to feed children, but though they were tuneful the mothers were slow to catch on. A local ballad singer was invited to tour the unit and see what was being taught. He composed a song which became one of the 'top ten' and was recorded. Likewise a local artist drew pictures for calendars using local proverbs, murals to decorate the walls and illustrations, depicting the richness of mixed foods, for the diplomas given to the mothers on discharge from the unit.

(4) 'Influencers'. The use of individuals who have a place of influence in society in carrying over a message is a much more doubtful strategy. Nevertheless half the in-patient accommodation was kept for influential club leaders, or the chief's wives, or local community leaders, so that they could reside for 2 weeks and undergo the same 'course' as the mothers of malnourished children and see for themselves the amazingly rapid improvement of the child on a good mixed diet. On discharge they are encouraged and supported to demonstrate and teach what they have learned in their local districts. The selection of these people requires again a close knowledge of the structure of society and 'order of peck'. Very often the most prestigious is of 
course the President's wife, and if she can be persuaded to breast-feed for instance, this has a salutary effect all the way down the line, providing there is no 'coup d'etat'.

(5) Indoctrination. The constant reiteration of four or five simple themes is of course the classical way of educating by rote and it still has a place. The aim is to achieve the maximum result through the minimum change. In fact the basic teaching in the nutrition rehabilitation unit in Kampala could be reduced to: (I) mix the staple with the sauce; (2) prepare the weaning child's food in a separate box for the whole day; (3) feed him at least four times per d; (4) carry on breastfeeding as a supplement for as long as you are able: four simple and not very extensive changes in the traditional routine, which could be plugged at every opportunity. Maurice King, an old friend of mine who has become famous for his textbooks for auxiliaries (e.g. King, 1967), uses 'axioms' as his basic teaching method; his books consist of a series of axioms which are then simply elaborated.

(6) Integration. To teach only nutrition would be unrealistic and meaningless, partly because there are so many other influences impinging on the malnourished child which need correction, and partly because nutrition itself spreads into many disciplines. The mothers were exposed to a 'barrage of experience' at the nutrition unit, encompassing the whole spectrum of village life. This was partly out of necessity, for we had to build a model house, cultivate a garden, keep a cow, grow trees, dig pit latrines, prevent flies, compost the crops, drain and irrigate in order to produce a rural centre into which mothers could be admitted and yet be self-sufficient. So we spread ourselves into the 'no man's land' between medicine and agriculture, education, forestry, building, community development, apart from the different fields of medicine itself such as family planning, antenatal care, hygiene, etc.

In so doing we became consumers, non-experts, seekers of advice, from different departments and realized how much life is compartmented vertically into specialities of ministries, each competing rather than co-ordinating their efforts. For the peasant, life is a whole and he does not see the divisions in daily living which have been created by the professions. Teaching therefore has to be integrated with many other disciplines so that at least there should be no contradictions of content or aim.

Integration of approach seems also necessary in urban deprived areas in this country and just as hard to attain. The nutritional problems of the children in these areas are only one aspect of the whole syndrome of deprivation and disadvantage where education is needed in home economics, hygiene, family planning, budgeting etc. as well as diet and nutrition.

(7) Individual. Initiative, imagination, innovation, and interest are desirable qualities of the individual teacher in any successful education. However good or bad the programme, the success will basically depend on the motives and intelligence of the individual teaching staff. Certainly the success of the nutrition unit in Kampala was due to the careful choice of staff.

It is essential however that their strength is nurtured properly, that they are given proper back-up; that they meet regularly and are listened to; that they are 
not left doing one routine, depressing job unrelieved for too long; that they have a varied responsibility so that they can refresh themselves at intervals; that they receive reasonable wages and leaves; and that they are given some means of evaluating their own work and responsibility for suggesting changes or modifications.

\section{Evaluation}

Evaluation of the results of nutrition education is important for three main reasons: ( 1 ) to provide confirmation or correction of method; (2) to motivate the staff; (3) to convince Government of the cost-effectiveness of a successful programme of nutrition education.

Evaluation can be counter-productive if it either involves large sums of extra money or staff which can distort the programme and produce unreal estimates, or is totally disregarded or suppressed, especially if the results show failure.

Three basic questions need to be asked. (I) What is the purpose of the evaluation? (2) How can it be done? (3) Who does it?

The answer to the first question divides itself into three again: (a) to establish what correlation, if any, exists between the outcome and the original education input; (b) to know if possible by what route the correlation has been achieved, whether by education, or by some other incidental positive factor, or both; (c) to know if possible where the block or bottleneck is, if failure is recorded.

(a) Correlation between outcome and teaching. We have to consider what outcome we want to measure and the length of time elapsing before measurement. Long-term evaluation is important, for it will measure more realietically the impact of work in which initial enthusiasm and supervision has subsided into routine management.

The immediate improvement of individual malnourished children demands only a record of their catch-up weights, the slopes of which can then be compared to the slope of the standard weight curve.

Further nutritional progress in rehabilitated children demands follow-up of weights to show long-term progress.

Malnutrition in younger sibs requires the follow-up of mother with regard to her next baby and a weight chart over the vulnerable weaning period.

The reduction of incidence of malnutrition in the neighbourhood of the programme requires attempted vital statistics with hospital, clinic and home visiting returns over the years.

The clinic staff can collect all the necessary data except for the last exercise during the course of their work. The data must be recorded in an easily retrievable and not necessarily computerized form. Visual weight records of a small cohort of children can be analysed very simply, and it can often be shared more easily with the staff.

(b) Routes of influence. It is important if possible to know the steps by which the teaching has influenced the child's nutrition. Little may separate the two in considering the immediate improvement of the individual child. Many more 
influences intervene when the duration between the teaching and measurement of its effect lengthens and the family and the community are considered.

Some of the steps by which input (education) may influence outcome (improved growth and health) can be shown thus:

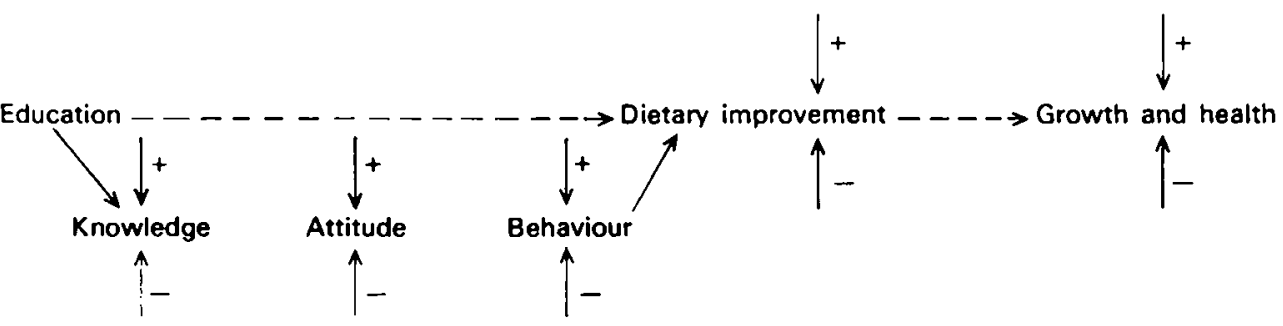

Therefore evaluation will need to show what changes of knowledge, attitude, behaviour and diet have occurred in the mothers, their contacts, and the community at large.

Some of this can be done by staff of the nutrition unit. The presence of simple 'markers' in the teaching, not present in the original culture, enable changes in a home or community to be traced back to the teaching at the unit: the distribution of calendars and whether they are hung on the wall; the state of the weight chart given to the mother; the appearance of a raised stove or a special cooking pot for the weaning child or the absence of feeding bottles; the singing of a song. These will give some idea of attitudes and behaviour.

Much of this work, however, may have to be done by a special 'evaluation' member of staff or team. Questionnaires for knowledge and attitude measurements need fairly sophisticated techniques. Behaviour changes will need to be noted by random home visiting, and dietary assessment.

(c) Intervening variables. Finally it may be necessary to know what factors impinging on the whole process are acting to neutralize or reverse the educational effect, or promote it, even to the extent of replacing it.

For instance, knowledge obviously is most directly and approximately linked with education but may be blocked by difficulties in bridging conceptual barriers as has been described.

Attitude, more distant, may be blocked from being influenced by knowledge through associations often having nothing to do with nutrition: political, emotional, or religious. Inhibitory influences such as pressure of commercial advertising, the modern pressures for women to work, to maintain good figures etc., are all operating against breast-feeding. The simplest unsuspected twist may be damaging to the whole teaching programme. Lack of motivation or a feeling of lack of relevance has already been discussed. Here one would listen to gossip, 'ear to the ground'; even 'bugging' helps, such as the tape recorder behind the mirror where the ladies collect to complete their toilet! We found, however, that the staff were the best evaluators of attitudes provided one took time to listen.

Behaviour may be inhibited even when knowledge and attitude are changed, because of constraints of conforming with the community, husband rejection, lack of resource, political or religious loyalties. 
Finally, there may be important influences operating on dietary improvement, growth and health which have nothing to do with ignorance, lack of knowledge and therefore with education. The most important of these was noted at the beginning, namely infection.

All these influences need analysing in order to apply necessary educational correctives and to perceive realistically the place of education in improving child nutrition.

The material presented in this paper is drawn from published work of King (1967), Church (1971), Robinson (1971), Schneideman, Bennett \& Rutishauser (1971), Jelliffe \& Jelliffe (197r) and McDowell \& Hoorweg (1975).

Much of what I have tried to describe was developed by my colleagues, Dr I. Schneideman, Mrs G. Stokes, Dr D. Robinson, and Dr M. A. Church who pioneered the work of the nutrition rehabilitation unit at Mulago Hospital, Kampala. Much of the evaluation of this unit has been achieved by I. McDowell and Dr J. Hoorweg.

\section{REFERENCES}

Church, M. A. (1971). J. trop. Pediat. envir. Child Hlth 17, Monogr. 13, p. 43.

Jelliffe, D. B. \& Jelliffe, E. P. (editors) (1971). Young Child Nutrition Programs. Evaluation and Guidelines. Zagreb: Young Child Nutrition Program.

King, M. (editor) (1967). Medical Care in Developing Countries. London: Oxford University Press.

McDowell, I. \& Hoorweg, J. (1975). Ecol. Fd Nutr. 4, 91.

Robinson, D. C. (1971). J. trop. Pediat. envir. Child Hith 17, Monogr. 13, p. 35.

Schneideman, I., Bennett, F. J. \& Rutishauser, I. H. E. (1971). F. trop. Pediat. envir. Child Hlth 17, Monogr. 13, p. 25. 